\title{
Measurement of mandibular lingula location using cone-beam computed tomography and internal oblique ridge-guided inferior alveolar nerve block
}

\author{
Ho-Yeol Jang ${ }^{1}$, Seung-Jung Han² \\ ${ }^{I}$ Department of Oral and Maxillofacial Surgery, Konyang University Hospital, Daejeon, \\ ${ }^{2}$ Medical \& Scientific Affairs Team, CGBio Research Center, Seongnam, Korea
}

\begin{abstract}
J Korean Assoc Oral Maxillofac Surg 2019;45:158-166)
Objectives: Inferior alveolar nerve block (IANB) is the most frequently used treatment for mandibular molars. Successful IANB requires insertion of the dental needle near the mandibular foramen. In this study, we aimed to analyze the anatomic location of the mandibular lingula and evaluate the effects of internal oblique ridge (IOR)-guided IANB.

Materials and Methods: The location of the mandibular lingula was measured using cone-beam computed tomography images of the mandibles obtained from 125 patients. We measured the distances from the occlusal plane to the lingula and from the IOR to the lingula in 250 mandibular rami. Based on the mean of these distances, alternative anesthesia was carried out on 300 patients, and the success rate of the technique was evaluated.

Results: The mean vertical distance was $8.85 \pm 2.59 \mathrm{~mm}$, and the mean horizontal distance was $14.68 \pm 1.44 \mathrm{~mm}$. The vertical $(P<0.001)$ and the horizontal $(P<0.05)$ distances showed significant differences between the sex groups. The success rate of the IOR-guided technique was $97.3 \%$.

Conclusion: IANB-based location of mandibular lingula showed a high success rate. From this study, we concluded that analysis of the anatomic locations for mandibular lingula and IOR-guided IANB are useful for restorative and surgical dental procedures of the mandibular molars.
\end{abstract}

Key words: Inferior alveolar nerve, Inferior alveolar nerve block, Lingula, Mandibular foramen, Internal oblique ridge

[paper submitted 2018. 12. 24 / revised 2019. 1. 9 / accepted 2019. 1. 9]

\section{Introduction}

The inferior alveolar nerve (IAN) passes through the inside of the mandible and controls the sensory system of the mandibular region, including the mandibular teeth, the gingiva of the mandible, and the lower lip. During restorative and surgical procedures performed in these areas, infiltration anesthesia is not sufficient because the mandible is surrounded with compact bone. The inferior alveolar nerve block (IANB) is the most commonly used technique for dental procedures to provide sufficient anesthesia, but numerous clinicians have experienced difficulty with the IANB because the clini-

\section{Ho-Yeol Jang}

Department of Oral and Maxillofacial Surgery, Konyang University Hospital, 158 Gwanjeodong-ro, Seo-gu, Daejeon 35365, Korea

TEL: +82-42-600-9235 FAX: +82-42-600-9095

E-mail:janghy5102@gmail.com

ORCID: https://orcid.org/0000-0001-5646-9535

(c) This is an open-access article distributed under the terms of the Creative Commons Attribution Non-Commercial License (http://creativecommons.org/ licenses/by-nc/4.0/), which permits unrestricted non-commercial use, distribution, and reproduction in any medium, provided the original work is properly cited.

Copyright (C) 2019 The Korean Association of Oral and Maxillofacial Surgeons. All rights reserved. cian has to insert the needle into the movable soft tissue and blindly access the mandibular foramen depending on sense of touch during the IANB. Various studies have reported that the IANB has a relatively high failure rate for local anesthesia of the oral region ${ }^{1-7}$.

Various techniques have been introduced to anesthetize the IAN; each technique has advantages and disadvantages. Both the clinician and the patient desire a predictable and successful IANB. If the clinician can accurately recognize the anatomic location of the mandibular foramen and inject the anesthetic in the pterygomandibular space, the success rate of the IANB would be raised. Therefore, an easily recognizable, anatomic landmark is needed for needle insertion. Moreover, anatomical studies of the mandible are also required to approach the mandibular foramen.

In this study, the anatomical location of the lingula existing in the inner surface of the ramus was measured using conebeam computed tomography (CBCT) analysis. The data were used as a reference for the approach of the needle to the mandibular foramen. The alternative IANB was performed using the internal oblique ridge (IOR) as an anatomic landmark, 
and its success rate was evaluated.

\section{Materials and Methods}

\section{Patients and methods}

1) Measuring the lingula location

This study included 125 patients who required extraction of the mandibular 3rd molar and who had CBCT taken in the Department of Oral and Maxillofacial Surgery, Konyang University Hospital (Daejeon, Korea) from May 2015 to August 2016. Patients whose occlusal plane (OP) could not be established because of the loss of the mandibular incisor or molar or who had lesions related to an impacted tooth were excluded. In total, 63 males and 62 females were enrolled in this study, and patient age ranged from 15 to 56 years with a mean age of $27.15 \pm 7.90$ years. The anatomic location of the lingula was measured by CBCT image analysis in 250 mandibular rami of the 125 patients.(Table 1 )

\section{2) IOR-guided IANB}

An IOR-guided IANB was carried out in 300 patients who

Table 1. Sex and age distribution of patients in cone-beam computed tomography analysis

\begin{tabular}{cccc}
\hline Age group $(\mathrm{yr})$ & Male $(\mathrm{n}=63)$ & Female $(\mathrm{n}=62)$ & Total $(\mathrm{n}=125)$ \\
\hline $10-19$ & 5 & 6 & $11(8.8)$ \\
$20-29$ & 40 & 39 & $79(63.2)$ \\
$30-39$ & 14 & 12 & $26(20.8)$ \\
$\geq 40$ & 4 & 5 & $9(7.2)$ \\
\hline
\end{tabular}

Values are presented as number only or number (\%).

Ho-Yeol Jang et al: Measurement of mandibular lingula location using cone-beam computed tomography and internal oblique ridge-guided inferior alveolar nerve block. $J$ Korean Assoc Oral Maxillofac Surg 2019 required extraction of the mandibular 3rd molar at the Department of Oral and Maxillofacial Surgery, Konyang University Hospital from August 2016 to February 2017. This study was approved by the Konyang University Hospital Institutional Review Board, and all participants signed an informed consent agreement prior to the study. A total of 133 male and 167 female patients were randomly selected for the IOR-guided IANB. The patients' ages ranged from 15 to 70 years with a mean age of $29.36 \pm 12.21$ years. The mandibular 3 rd molars were extracted in 168 sites on the right and in 132 sites on the left for a total of 300 sites.(Table 2)

\section{Study method}

1) Measuring of lingula location

The CBCT images were reconstructed in three dimensions (3D) using Ez3D-I software (Vatech Korea, Seoul, Korea), and the mandible was separated using the eraser function in 3D images for exact measuring.(Fig. 1. A) The OP was set up with a plane between the tip of the mandibular central incisor and the mesiobuccal cusps of both mandibular 2nd molars.

Table 2. Sex and age distribution of patients for inferior alveolar nerve block

\begin{tabular}{cccc}
\hline Age group $(\mathrm{yr})$ & Male $(\mathrm{n}=133)$ & Female $(\mathrm{n}=167)$ & Total $(\mathrm{n}=300)$ \\
\hline $10-19$ & 30 & 21 & $51(17.0)$ \\
$20-29$ & 57 & 93 & $150(50.0)$ \\
$30-39$ & 18 & 20 & $38(12.7)$ \\
$40-49$ & 16 & 20 & $36(12.0)$ \\
$\geq 50$ & 12 & 13 & $25(8.3)$ \\
\hline
\end{tabular}

Values are presented as number only or number (\%).

Ho-Yeol Jang et al: Measurement of mandibular lingula location using cone-beam computed tomography and internal oblique ridge-guided inferior alveolar nerve block. $J$ Korean Assoc Oral Maxillofac Surg 2019
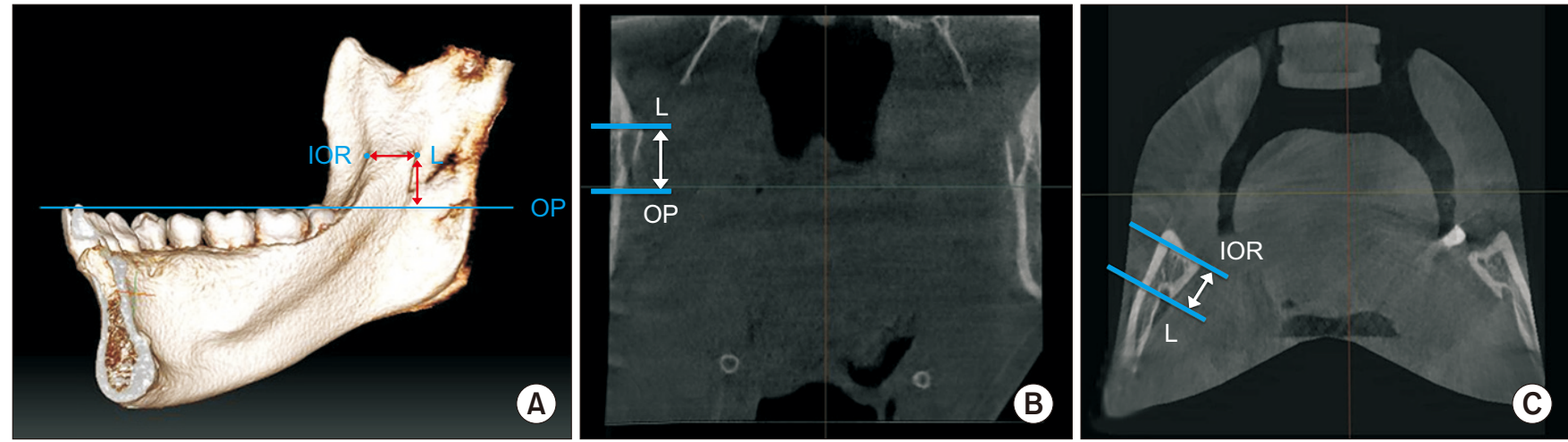

Fig. 1. Measuring of lingula location using cone-beam computed tomography (CBCT) analysis. $A$. three-dimensional reconstruction of CBCT images. B. Vertical distance (OP-L) in the coronal view. C. Horizontal distance (IOR-L) in the axial view. (L: lingula, IOR: internal oblique ridge, IOR-L: distance from IOR to lingula, OP: occlusal plane, OP-L: distance from OP to lingula)

Ho-Yeol Jang et al: Measurement of mandibular lingula location using cone-beam computed tomography and internal oblique ridge-guided inferior alveolar nerve block. J Korean Assoc Oral Maxillofac Surg 2019 
In the $\mathrm{CBCT}$ coronal view, the reference landmark of the measuring point was set on the mandibular lingula (L). Next, the vertical distance was measured from the OP to the lingula (OP-L).(Fig. 1. B) In the CBCT axial view, the measuring points were set on the IOR and L. The horizontal distance paralleling the OP was measured from the IOR to the lingula (IOR-L).(Fig. 1. C) To reduce personal errors that may occur in setting the reference point and measuring distances, the CBCT analyses of all patients were performed by the same researcher.

\section{2) IOR-guided IANB}

The IOR-guided IANB was carried out for the extraction of 3rd molar based on the mean location of the mandibular lingula from the previous CBCT analysis.(Fig. 2, 3) To minimize personal errors from different clinicians, all anesthesia procedures were performed by the same oral-maxillofacial surgeon. The $2 \%$ lidocaine cartilage included 1:100,000 epinephrine, and a 27 gauge and $32 \mathrm{~mm}$ dental needle was used in the IANB.

\section{Technique}

1) The IOR of the ramus anterior border was detected by palpation using the thumb or index finger.(Fig. 3. A)

2) The soft tissue was retracted laterally with the finger to determine an approximate insertion point from 8 to $10 \mathrm{~mm}$ above the OP. The bevel of the needle tip was directed parallel with inner surface of the ramus to prevent damage to the periosteum.

3) The barrel of the syringe was placed in the canine or first premolar of the contralateral side of the extraction, and the
A

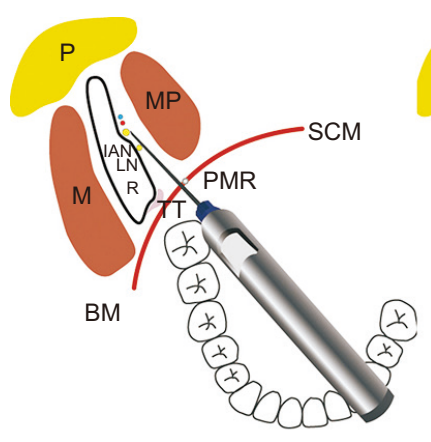

B

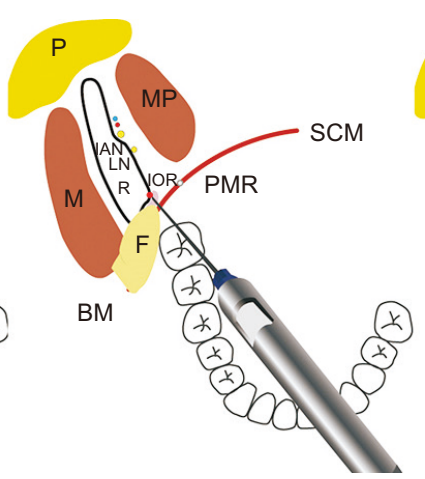

C

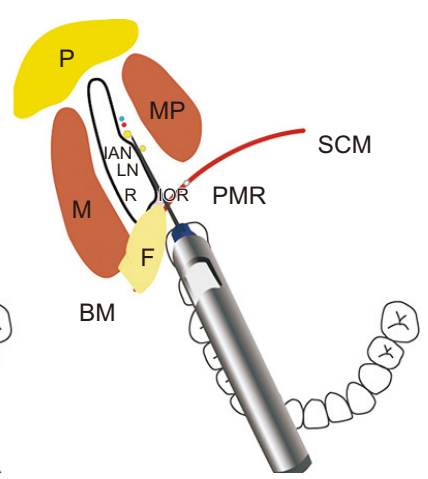

Fig. 2. Comparison diagram of conventional inferior alveolar nerve block (IANB) and internal oblique ridge (IOR)-guided IANB. A. Needle pathway in conventional IANB. B. Needle insertion on IOR after finger palpation. C. Needle access to lingula along medial periosteum of ramus. (P: parotid gland, M: masseter muscle, MP: medial pterygoid muscle, IAN: inferior alveolar nerve, LN: lingual nerve, R: ramus, BM: buccinator muscle, SCM: superior constrictor muscle, T: temporalis tendon, PMR: pterygomandibular raphe, F: finger palpation and retraction)

Ho-Yeol Jang et al: Measurement of mandibular lingula location using cone-beam computed tomography and internal oblique ridge-guided inferior alveolar nerve block. J Korean Assoc Oral Maxillofac Surg 2019
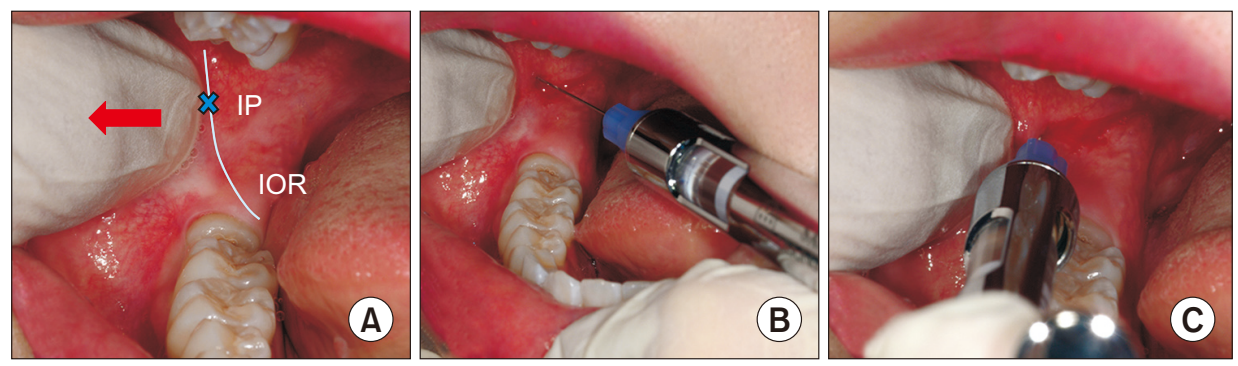

Fig. 3. Internal oblique ridge (IOR)-guided inferior alveolar nerve block technique. A. Palpation of the IOR and lateral retraction of soft tissue. Arrow: finger retraction. B. Initial insertion of needle toward IOR. C. Needle insertion near the mandibular foramen along medial periosteum of ramus. (IP: insertion point)

Ho-Yeol Jang et al: Measurement of mandibular lingula location using cone-beam computed tomography and internal oblique ridge-guided inferior alveolar nerve block. J Korean Assoc Oral Maxillofac Surg 2019 
needle was inserted at the prepared point of the IOR.(Fig. 2. B, 3. B)

4) After the needle tip was in contact with the IOR, the needle was moved about 23 to $25 \mathrm{~mm}$ posteriorly, until it was near the mandibular lingula along the medial periosteum of the ramus parallel to the OP.(Fig. 2. C, 3. C) The insertion depth of 23 to $25 \mathrm{~mm}$ was determined by totaling the mean $14.68 \pm 1.44 \mathrm{~mm}$ distance of IOR-L obtained in measurement analysis of this study, the soft tissue thickness of insertion the point, and the width of the mandibular foramen. As the needle was advanced more deeply, the barrel of the syringe was adjusted toward the ipsilateral side of the extraction. This process can decrease the resistance of muscle and connective tissue and help move the needle smoothly in the pterygomandibular space.

5) After ensuring that there was no blood aspiration, $2 \mathrm{~mL}$ of anesthetic were injected.

6) To etherize the long buccal nerve, $1 \mathrm{~mL}$ of anesthetic solution was injected at the distobuccal mucosa of the mandibular 2nd molar. No separate anesthesia was done for the lingual nerve.

7) If the patient expressed numbness on the ipsilateral lower lip and tongue after 8 to 10 minutes, the mandibular 3rd molar extraction was performed.

\section{Success Rate of IOR-guided Technique}

If the patients did not express any pain during extraction and no additional anesthesia was needed, the anesthesia was deemed successful. If patients did not feel numbness of the lower lip after anesthesia or expressed pain during the extraction, the anesthesia was classified as a failure.

Table 3. Distances to lingula from mandibular landmarks

\begin{tabular}{clccc}
\hline Distance & Side & Mean \pm SD & Minimum & Maximum \\
\hline $\begin{array}{c}\text { OP-L } \\
(\mathrm{mm})\end{array}$ & $\begin{array}{l}\text { Right } \\
(\mathrm{n}=125)\end{array}$ & $8.93 \pm 2.71$ & 4.1 & 16.4 \\
& $\begin{array}{l}\text { Left } \\
(\mathrm{n}=125)\end{array}$ & $8.76 \pm 2.57$ & 3.9 & 16.9 \\
& $\begin{array}{l}\text { Both } \\
(\mathrm{n}=250)\end{array}$ & $8.85 \pm 2.59$ & 3.9 & 16.9 \\
$\begin{array}{c}\text { IOR-L } \\
(\mathrm{mm})\end{array}$ & $\begin{array}{l}\text { Right } \\
(\mathrm{n}=125) \\
\text { Left } \\
(\mathrm{n}=125)\end{array}$ & $14.55 \pm 1.63$ & 10 & 18.5 \\
& $\begin{array}{l}\text { Both } \\
(\mathrm{n}=250)\end{array}$ & $14.68 \pm 1.44$ & 10 & 19 \\
\hline
\end{tabular}

(OP-L: distance from occlusal plane to lingula, IOR-L: distance from internal oblique ridge to lingula, SD: standard deviation)

Ho-Yeol Jang et al: Measurement of mandibular lingula location using cone-beam computed tomography and internal oblique ridge-guided inferior alveolar nerve block. $J$ Korean Assoc Oral Maxillofac Surg 2019

\section{Statistical analyses}

Statistical analyses of data were performed using PASW Statistics 18.0 software (IBM, Armonk, NY, USA). OP-L and IOR-L were analyzed by frequency analysis. The independent t-test was used for comparisons of OP-L and IOR-L between sex groups. A one-way ANOVA was used for comparisons of OP-L and IOR-L between age groups. In both tests, a level of $P<0.05$ was considered statistically significant.

\section{Results}

\section{Location of the mandibular lingula}

The mean vertical distances (OP-L) were $8.93 \pm 2.71 \mathrm{~mm}$ on the right ramus, $8.76 \pm 2.57 \mathrm{~mm}$ on the left ramus, and $8.85 \pm 2.59 \mathrm{~mm}$ on both rami.(Table 3 ) The mean horizontal IOR-L distances were $14.55 \pm 1.63 \mathrm{~mm}$ on the right ramus, $14.82 \pm 1.44 \mathrm{~mm}$ on the left ramus, and $14.68 \pm 1.44 \mathrm{~mm}$ on both rami in level of the lingula. The OP-L distance has a more personal variation than the IOR-L distance.(Table 3) The mean OP-L distances were $10.30 \pm 2.33 \mathrm{~mm}$ in males and $7.37 \pm 1.94 \mathrm{~mm}$ in females. There was a statistically significant difference in the OP-L distances $(P<0.001)$ between sex groups.(Table 4) The mean IOR-L distances were 14.99 \pm 1.27 $\mathrm{mm}$ in males and $14.37 \pm 1.55 \mathrm{~mm}$ in females. There was a statistically significant difference in the IOR-L distances $(P<0.05)$ between the sex groups. (Table 4$)$ Both the IOR-L and OP-L distances of males were analyzed to be relatively longer than females. There were statistically significant differences in the left $(P<0.05)$ IOR-L distance and both $(P<0.05)$ of IOR-L distances between the age groups.(Table 5)

Table 4. Comparison of distance to lingula from mandibular landmarks between sex

\begin{tabular}{cllcc}
\hline Distance & Side & Male $(\mathrm{n}=63)$ & Female $(\mathrm{n}=62)$ & $P$-value \\
\hline OP-L & Right & $10.42 \pm 2.52$ & $7.42 \pm 1.97$ & $<0.001^{* *}$ \\
$(\mathrm{~mm})$ & Left & $10.19 \pm 2.28$ & $7.31 \pm 1.98$ & $<0.001^{* *}$ \\
& Both & $10.30 \pm 2.33$ & $7.37 \pm 1.94$ & $<0.001^{* *}$ \\
IOR-L & Right & $14.88 \pm 1.42$ & $14.20 \pm 1.76$ & $0.020^{*}$ \\
$(\mathrm{~mm})$ & Left & $15.10 \pm 1.35$ & $14.53 \pm 1.48$ & $0.026^{*}$ \\
& Both & $14.99 \pm 1.27$ & $14.37 \pm 1.55$ & $0.015^{*}$ \\
\hline
\end{tabular}

(OP-L: distance from occlusal plane to lingula, IOR-L: distance from internal oblique ridge to lingula)

$* P<0.05, * * P<0.001$

Values are presented as mean \pm standard deviation.

Ho-Yeol Jang et al: Measurement of mandibular lingula location using cone-beam computed tomography and internal oblique ridge-guided inferior alveolar nerve block. $J$ Korean Assoc Oral Maxillofac Surg 2019 
Table 5. Comparison of distance to lingula from mandibular landmarks in different age groups

\begin{tabular}{|c|c|c|c|c|c|c|}
\hline \multirow{2}{*}{ Distance } & \multirow{2}{*}{ Side } & \multicolumn{4}{|c|}{ Age group (yr) } & \multirow{2}{*}{$P$-value } \\
\hline & & $10-19(n=6)$ & $20-29(n=29)$ & $30-39(n=13)$ & $\geq 40(n=2)$ & \\
\hline \multirow{3}{*}{$\begin{array}{l}\text { OP-L } \\
(\mathrm{mm})\end{array}$} & Right & $10.06 \pm 2.89$ & $8.80 \pm 2.65$ & $9.02 \pm 2.95$ & $8.46 \pm 2.31$ & 0.496 \\
\hline & Left & $9.98 \pm 2.93$ & $8.62 \pm 2.53$ & $8.79 \pm 2.72$ & $8.41 \pm 2.05$ & 0.414 \\
\hline & Both & $10.02 \pm 2.86$ & $8.71 \pm 2.53$ & $8.91 \pm 2.80$ & $8.43 \pm 2.16$ & 0.440 \\
\hline \multirow{3}{*}{$\begin{array}{r}\text { IOR-L } \\
(\mathrm{mm})\end{array}$} & Right & $14.59 \pm 1.24$ & $14.80 \pm 1.52$ & $13.98 \pm 1.69$ & $13.90 \pm 2.39$ & 0.093 \\
\hline & Left & $14.85 \pm 1.05^{\mathrm{ab}}$ & $15.12 \pm 1.37^{\mathrm{a}}$ & $14.24 \pm 1.53^{\mathrm{b}}$ & $13.86 \pm 1.45^{\mathrm{b}}$ & $0.008 *$ \\
\hline & Both & $14.72 \pm 1.07^{\mathrm{ab}}$ & $14.96 \pm 1.35^{\mathrm{a}}$ & $14.11 \pm 1.50^{\mathrm{b}}$ & $13.88 \pm 1.87^{\mathrm{b}}$ & $0.019 *$ \\
\hline
\end{tabular}

(OP-L: distance from occlusal plane to lingula, IOR-L: distance from internal oblique ridge to lingula)

$* P<0.05$.

${ }^{\mathrm{ab}}$ The same characters were not significant by the least significant difference (LSD) test.

Values are presented as mean \pm standard deviation.

Ho-Yeol Jang et al: Measurement of mandibular lingula location using cone-beam computed tomography and internal oblique ridge-guided inferior alveolar nerve block. J Korean Assoc Oral Maxillofac Surg 2019

Table 6. Success rate of alternative inferior alveolar nerve block (IANB) $(n=300)$

\begin{tabular}{lc}
\hline Response after alternative IANB & Value \\
\hline Lower lip numbness & $292(97.3)$ \\
Additional anesthesia & $5(1.7)$ \\
Pain on extraction & $3(1.0)$ \\
\hline
\end{tabular}

Values are presented as number (\%).

Ho-Yeol Jang et al: Measurement of mandibular lingula location using cone-beam computed tomography and internal oblique ridge-guided inferior alveolar nerve block. $J$ Korean Assoc Oral Maxillofac Surg 2019

\section{Success rate of IOR-guided technique}

The success rate of the IOR-guided technique was $97.3 \%$. (Table 6) Extractions of the mandibular 3rd molar were performed successfully in 292 patients without additional anesthesia. However, five patients who did not feel numbness of the lower lip after the initial anesthesia needed additional anesthesia. Three patients needed additional anesthesia due to pain during extraction. Complications related to anesthesia, including nerve injury, trismus, hematoma, and needle breakage, did not occur.

\section{Discussion}

Current anatomic studies on the location of the mandibular foramen have mostly been performed using dry mandibles ${ }^{8-15}$. The results of these studies are relatively accurate because a dry mandible can be measured directly. However, information on dry mandibles regarding sex and age is limited, so comparison and analysis measuring the values is difficult. And a dry mandible, which has both intact dentition and an OP, is expensive and difficult to find. More recently, measuring a variety of anatomical measurements has become possible using computers. This is because software has been developed that can make $3 \mathrm{D}$ reconstructions and analyses us- ing a patient's computed tomography (CT) images. These CT data are more convenient and inexpensive than those of a dry mandible. Also, researchers can set up various anatomic landmarks and make a virtual line in the software images. Thus, computer reconstruction allows for a complex measurement of the distance or the angle more easily than in a dry mandible studies. These data can be used in systematic and accurate analyses related to sex or age. In this study, a 3D mandibular model was made with the patient's CBCT images and then vertical and horizontal locations of the mandibular lingula were measured and analyzed.

Many authors have used different landmarks, such as the mandibular foramen or the lingula, to analyze the location of the IAN ${ }^{8-18}$. The level of the mandibular lingula is a more useful landmark than the level of the mandibular foramen when a clinician determines the vertical target of the anesthetic needle in an IANB, because an IANB actually attempts to anesthetize the IAN around the mandibular lingula prior to it entering the mandibular foramen. Therefore, in this study, the location of the mandibular lingula was also measured as an anatomical landmark. Many results have been published about the antero-posterior location of the mandibular lingula or the mandibular foramen. According to Jansisyanont et al. ${ }^{8}$ and $\mathrm{Yu}$ et al. ${ }^{16}$, the lingula was positioned at $20.6 \mathrm{~mm}$ and $17.7 \mathrm{~mm}$, respectively, from the anterior border of the ramus. Monnazzi et al. ${ }^{9}$ noted a mean distance of $17.67 \mathrm{~mm}$ from the anterior border of the ramus to the mandibular foramen. Oguz and Bozkir ${ }^{10}$ showed results with $16.9 \mathrm{~mm}$ on the right and $16.78 \mathrm{~mm}$ on the left. The distance from the IOR to the mandibular foramen was shorter than the distance from the anterior border of the ramus to the mandibular foramen ${ }^{11,12}$. Ennes and Medeiros ${ }^{11}$ and Viravudth and Plakornkul ${ }^{12}$ found $14.6 \mathrm{~mm}$ and $14.33 \mathrm{~mm}$, respectively, as the mean distances from the IOR to the mandibular foramen. In this study, the 
mean distance from the IOR of the ramus to the lingula was $14.68 \pm 1.44 \mathrm{~mm}$, and this distance is similar to the results of Ennes and Medeiros ${ }^{11}$.(Table 3)

To determine the horizontal insertion depth of the needle, the clinician should consider the thickness of the oral mucosa of the insertion point and the location of the IAN, which enters from the back of the lingula into the mandibular foramen. Many authors recommended an insertion depth of 20 to 25 $\mathrm{mm}$ to closely approach the mandibular foramen ${ }^{1,8,13}$. In this study, the insertion depth of the needle was determined to be 23 to $25 \mathrm{~mm}$; this length was calculated by totaling the mean $14.68 \pm 1.44 \mathrm{~mm}$ of the IOR-L distance of this study, $4.7 \mathrm{~mm}$ of mandibular foramen width ${ }^{8}$, and $4.12 \mathrm{~mm}$ of the mucosal thickness ${ }^{19}$.

The mandibular foramen and the mandibular lingula vary in vertical location in each individual. Nicholson described that the mandibular foramen is located almost below the $\mathrm{OP}^{14}$. However, Hwang et al. ${ }^{17}$ and Kang et al. ${ }^{18}$ stated that mandibular foramina are located $4.16 \mathrm{~mm}$ and $3.8 \mathrm{~mm}$, respectively, above the OP in adults. Jansisyanont et al.8 reported that the lingula is located $4.5 \mathrm{~mm}$ above the OP. In this study, the mean OP-L vertical distance was measured to be $8.85 \pm 2.59 \mathrm{~mm}$ from the OP to the mandibular lingula.(Table 3) The OP-L vertical distance has more individual variation than the IOR-L horizontal distance, and both the OP-L vertical distance and the IOR-L horizontal distance in males were relatively longer than those in females.(Table 4) In many studies, the insertion level of the needle was recommended to be set at 8 to $10 \mathrm{~mm}$ above the $\mathrm{OP}^{1,13,15}$. If the insertion level of the needle is adjusted vertically from $8.85 \pm 2.59 \mathrm{~mm}$ of the mean OP-L vertical distance, taking into consideration the patient's information, such as sex, age, and panorama radiography, the success rate of the anesthesia increases.

Infiltration anesthesia is very effective in the maxilla without block anesthesia because the maxilla has a larger volume of cancellous bone. However, block anesthesia is needed for restorative and surgical procedures of a mandibular molar because the mandible is surrounded by thick compact bone, and the infiltration of the anesthetic solution is limited. Since Halstead introduced the first block anesthesia, many authors have described various techniques for the IANB ${ }^{20}$. Among them, the conventional IANB has commonly been used to achieve IAN anesthesia. The needle is inserted parallel to the OP and from the premolars on the contralateral side. The insertion point is determined at the soft tissue lateral to the pterygomandibular raphe and above 8 to $10 \mathrm{~mm}$ from the OP. The needle is inserted through the mucosa and ap- proaches near the mandibular foramen of the inner ramus and then the anesthetic solution is given after aspiration. In the IANB, the anesthetic solution should be injected near the IAN located inside the pterygomandibular space. Thus, the clinician should consider both the anatomy of the IAN and the pterygomandibular space. The boundaries of each pterygomandibular space are the medial pterygoid muscle medially, the ascending ramus of the mandible laterally, the lateral pterygoid muscle superiorly, the posterior border of the buccal space anteriorly, and the parotid gland posteriorly. The pterygomandibular space contains the IAN, the lingual nerve, the inferior alveolar vessel, and the sphenomandibular ligament. The IAN passes along the pterygomandibular space through a narrow space between the medial pterygoid muscle and the lateral pterygoid muscle; it enters into the mandibular foramen and is distributed widely throughout the mandible. The lingual nerve passes more antero-medially than the IAN in the pterygomandibular space. The lingual nerve is commonly blocked together with the IAN by an IANB.

The success rate of an IANB depends greatly on the skill and experience of clinician. It has a relatively high failure rate $(15 \%-35 \%)^{1-3}$. Also, clinical studies in endodontics have found a high failure rate $(38 \%-75 \%)$ with the IANB. This is related to the inflammatory condition of the pulp ${ }^{4-7}$. Many authors have described that a variable location of the mandibular foramen raises the failure rate of an $\mathrm{IANB}^{21-24}$. For the success of an IANB, the needle should approach as close as possible to the IAN or the mandibular foramen on the pterygomandibular space.

Many alternative techniques for the IANB have been described to achieve satisfactory success and reduce complications $^{25-31}$. Thangavelu et al. ${ }^{25}$ introduced an alternative technique with a high success rate of $95 \%$. In this technique, the first insertion point is 6 to $8 \mathrm{~mm}$ above the coronoid notch and 8 to $10 \mathrm{~mm}$ posterior from the anterior border of the ramus, and then the barrel of the syringe is adjusted toward the midline and the mandibular foramen approaches along the medial side of the ramus. This technique has a different needle insertion point than the IOR-guided technique, but both techniques are similar in needle movement along the inner periosteum of the ramus. Chakranarayan and Mukherjee ${ }^{26}$ introduced the arched needle technique for the IANB where, after insertion, the needle is arched and inserted in a manner whereby it approaches the medial surface of the ramus at an angle almost perpendicular to it. A success rate of $98 \%$ was obtained, but this technique has the potential for needle breakage and damage to the soft tissue. Boonsiriseth et al. ${ }^{27}$ 
introduced a novel injection approach in which the barrel of the syringe is placed on the occlusal surface of the posterior teeth at the same operation site. The needle insertion point is the same point as for the conventional IANB. This technique has the advantage of eliminating pain from the needle traumatizing the periosteum and bone. Suazo Galdames et al. ${ }^{28}$ introduced an alternative technique whereby the anesthetic is applied to the IAN via the retromolar triangle. According to their study, the needle is presented between the mandibular canal and variable holes of the retromolar triangle, through which the infiltration of an anesthetic solution would be possible. Even though this technique has a high failure rate of $27.5 \%$, it can be used to minimize the complications for patients with blood dyscrasias. Takasugi et al. ${ }^{29}$ introduced an anterior technique in which the needle is inserted to a depth of $10 \mathrm{~mm}$, and the anesthetic solution is injected into the anterior region of the pterygomandibular space. This technique was developed so that anesthesia can be delivered to the IAN with a lower risk of inferior alveolar neural and vascular complications; however, the success rate of this technique is relatively low (75\%). The Gow-Gates technique ${ }^{30}$ and Akinosi technique ${ }^{31}$ block the mandibular nerve trunk directly in the more upper position than the conventional IANB. Despite the fact that both techniques are very useful in some patients when the clinician cannot use the conventional IANB, most clinicians do not often use either technique because separate skillsets are required and the anesthetic latency is too late.

In conventional IANB, many clinicians have difficulty determining the insertion point and depth of the needle. This is due to the mobilization of the soft tissue during needle insertion and because penetration is through multiple layers of anatomic structure. For a successful IANB, a definite point of reference is required at the needle insertion. Alternative IANBs using the IOR as the reference point were performed in this study. After detection of the IOR, located 8 to $10 \mathrm{~mm}$ above the OP, the needle is inserted to a 23 to $25 \mathrm{~mm}$ depth along the medial periosteum of the ramus; then, the anesthetic is injected around the mandibular lingula. In this alternative technique, the clinicians can more easily determine the injection point with a rigid and stable IOR. The needle can reach near to the mandibular lingula without resistance, and damage to the soft tissue can be prevented because the needle moves along the medial periosteum of the ramus.

When we performed the IANB using the IOR in this study, anesthetic failure occurred in only eight patients $(2.7 \%)$. (Table 6) This is a lower failure rate than experienced using other IANB techniques. The causes of failure was not clear, but some possibilities are assumed. The needle and the anesthetic solution could not approach around the mandibular foramen because of a severe anatomical variation in the mandibular foramen or an accessory branch of the IAN ${ }^{14,21-24}$. If the needle is inserted into a malposition instead of the IAN around the mandibular foramen, various complications can occur, such as damage to the soft tissue, swelling, pain, and trismus $^{32,33}$. The needle may fracture if the clinician applies excessive force ${ }^{34}$. If the needle is positioned too posteriorly, the anesthetic may be diffused into the parotid gland, which may cause transient paralysis of the facial nerve $e^{35}$. If the needle is positioned too high and deep, the auriculotemporal nerve can be anesthetized, and numbness around the ear can occur. Especially if the anesthetic solution is injected into the lateral pterygomandibular muscle, pain, trismus, and disorders of the temporomandibular joint can be induced. If the pterygomandibular vessel or the pterygoid venous plexus is damaged by needle insertion, a hematoma can occur in the pterygomandibular space ${ }^{21}$. Most complications can be resolved in a short time, but any unexpected complication may affect the relationship between the patient and the clinician if it occurs after anesthesia. In this study, complications did not occur because a clear reference, such as the IOR, was used in the needle insertion, and the anesthetic solution was injected taking into consideration the mean location of the mandibular lingula.

In this study, all analyses were carried out using only hard tissue associated with the location of the mandibular lingula. To increase the success rate of an IANB, soft tissue also needs to be considered. Additional studies regarding the thickness of oral mucosa, where the needle is inserted, and the size of the pterygomandibular space where the anesthetic is injected, are necessary. In addition, the OP can change according to malocclusion, prosthetics, sex, or age, which can lead to measurement errors or anesthesia failure. Additional studies of these variables are needed.

\section{Conclusion}

In this study, the anatomical location of the mandibular lingula and the mean distance throughout 3D reconstruction were measured and analyzed utilizing CBCT images. The insertion level and depth of the anesthetic needle were determined based on mean vertical and horizontal distances of the mandibular lingula. We attempted an alternative IANB where the dental needle was inserted via the IOR and approached the lingula along the medial periosteum of the mandibular 
ramus; the anesthetic solution was injected near the mandibular lingula on the pterygomandibular space. This technique is easier and safer for the clinician than the conventional IANB because the anesthetic needle is inserted using the IOR, which is a consistent reference point and approaches the mandibular lingula freely inside the pterygomandibular space. The IOR-guided IANB showed a 97.3\% success rate without special complications. Therefore, this study concludes that the anatomical location of the mandibular lingula should be considered in an IANB, and that the IOR-guided IANB is very useful for surgical procedures of the mandibular molar region.

\section{ORCID}

\section{Ho-Yeol Jang, https://orcid.org/0000-0001-5646-9535 \\ Seung-Jung Han, https://orcid.org/0000-0002-4038-6118}

\section{Authors' Contributions}

H.Y.J. participated in data collection and wrote the manuscript. S.J.H. participated in the study design and coordination and helped to draft the manuscript. All authors read and approved the final manuscript.

\section{Acknowledgements}

This work was supported by the National Research Foundation of Korea (NRF) grant funded by the Korea government (MSIP; Ministry of Science, ICT \& Future Planning) (No. 2017B0070).

\section{Ethics Approval and Consent to Participate}

All procedures performed in studies involving human participants were in accordance with the ethical standards of Konyang University Hospital Institutional Review Board, Daejeon, Korea (protocol No. 2016-06-012-001), and with the 1964 the Declaration of Helsinki and its later amendments or comparable ethical standards. Informed consent was obtained from all individual participants included in the study.

\section{Conflict of Interest}

No potential conflict of interest relevant to this article was reported.

\section{References}

1. Petrikas AZh, Ol'khovskaia EB, Medvedev DV, Diubaĭlo MV. [Disputable issues of Malamed's "Handbook of local anesthesia" (2004)]. Stomatologiia (Mosk) 2013;92:71-6. Russian.

2. Robertson WD. Clinical evaluation of mandibular conduction anesthesia. Gen Dent 1979;27:49-51.

3. Levy TP. An assessment of the Gow-Gates mandibular block for third molar surgery. J Am Dent Assoc 1981;103:37-41.

4. Cohen HP, Cha BY, Spångberg LS. Endodontic anesthesia in mandibular molars: a clinical study. J Endod 1993;19:370-3.

5. Reisman D, Reader A, Nist R, Beck M, Weaver J. Anesthetic efficacy of the supplemental intraosseous injection of 3\% mepivacaine in irreversible pulpitis. Oral Surg Oral Med Oral Pathol Oral Radiol Endod 1997;84:676-82.

6. Potocnik I, Bajrović F. Failure of inferior alveolar nerve block in endodontics. Endod Dent Traumatol 1999;15:247-51.

7. Nusstein J, Reader A, Nist R, Beck M, Meyers WJ. Anesthetic efficacy of the supplemental intraosseous injection of $2 \%$ lidocaine with 1:100,000 epinephrine in irreversible pulpitis. J Endod 1998;24:487-91.

8. Jansisyanont P, Apinhasmit W, Chompoopong S. Shape, height, and location of the lingula for sagittal ramus osteotomy in Thais. Clin Anat 2009;22:787-93.

9. Monnazzi MS, Passeri LA, Gabrielli MF, Bolini PD, de Carvalho WR, da Costa Machado H. Anatomic study of the mandibular foramen, lingula and antilingula in dry mandibles, and its statistical relationship between the true lingula and the antilingula. Int J Oral Maxillofac Surg 2012;41:74-8.

10. Oguz O, Bozkir MG. Evaluation of location of mandibular and mental foramina in dry, young, adult human male, dentulous mandibles. West Indian Med J 2002;51:14-6.

11. Ennes JP, Medeiros RM. Localization of mandibular foramen and clinical implications. Int J Morphol 2009;27:1305-11.

12. Viravudth Y, Plakornkul V. The mandibular foramen in Thais. Siriraj Med J 1989;41:551-4.

13. Bremer G. Measurements of special significance in connection with anesthesia of the inferior alveolar nerve. Oral Surg Oral Med Oral Pathol 1952;5:966-88.

14. Nicholson ML. A study of the position of the mandibular foramen in the adult human mandible. Anat Rec 1985;212:110-2.

15. Thangavelu K, Kannan R, Kumar NS, Rethish E, Sabitha S, Sayeeganesh N. Significance of localization of mandibular foramen in an inferior alveolar nerve block. J Nat Sci Biol Med 2012;3:15660.

16. Yu IH, Wong YK. Evaluation of mandibular anatomy related to sagittal split ramus osteotomy using 3-dimensional computed tomography scan images. Int J Oral Maxillofac Surg 2008;37:521-8.

17. Hwang TJ, Hsu SC, Huang QF, Guo MK. [Age changes in location of mandibular foramen]. Zhonghua Ya Yi Xue Hui Za Zhi 1990;9:98-103. Chinese.

18. Kang SH, Byun IY, Kim JH, Park HK, Kim MK. Three-dimensional anatomic analysis of mandibular foramen with mandibular anatomic landmarks for inferior alveolar nerve block anesthesia. Oral Surg Oral Med Oral Pathol Oral Radiol 2013;115:e17-23.

19. Müller HP, Schaller N, Eger T, Heinecke A. Thickness of masticatory mucosa. J Clin Periodontol 2000;27:431-6.

20. Matas R. The story of the discovery of dental anesthesia by nerve blocking; achievements of William Stewart Halsted. Surgery 1952;32:530-7.

21. Wong MK, Jacobsen PL. Reasons for local anesthesia failures. J Am Dent Assoc 1992;123:69-73.

22. Grover PS, Lorton L. Bifid mandibular nerve as a possible cause of inadequate anesthesia in the mandible. J Oral Maxillofac Surg $1983 ; 41: 177-9$.

23. Roda RS, Blanton PL. The anatomy of local anesthesia. Quintessence Int 1994;25:27-38. 
24. Sillanpää M, Vuori V, Lehtinen R. The mylohyoid nerve and mandibular anesthesia. Int J Oral Maxillofac Surg 1988;17:206-7.

25. Thangavelu K, Kannan R, Kumar NS. Inferior alveolar nerve block: alternative technique. Anesth Essays Res 2012;6:53-7.

26. Chakranarayan A, Mukherjee B. Arched needle technique for inferior alveolar mandibular nerve block. J Maxillofac Oral Surg 2013;12:113-6.

27. Boonsiriseth K, Sirintawat N, Arunakul K, Wongsirichat N. Comparative study of the novel and conventional injection approach for inferior alveolar nerve block. Int J Oral Maxillofac Surg 2013;42:852-6.

28. Suazo Galdames IC, Cantín López MG, Zavando Matamala DA. Inferior alveolar nerve block anesthesia via the retromolar triangle, an alternative for patients with blood dyscrasias. Med Oral Patol Oral Cir Bucal 2008;13:E43-7.

29. Takasugi Y, Furuya H, Moriya K, Okamoto Y. Clinical evaluation of inferior alveolar nerve block by injection into the pterygomandibular space anterior to the mandibular foramen. Anesth Prog 2000;47:125-9.

30. Gow-Gates GA. Mandibular conduction anesthesia: a new technique using extraoral landmarks. Oral Surg Oral Med Oral Pathol 1973;36:321-8.

31. Akinosi JO. A new approach to the mandibular nerve block. Br J
Oral Surg 1977; 15:83-7.

32. Smyth J, Marley J. An unusual delayed complication of inferior alveolar nerve block. Br J Oral Maxillofac Surg 2010;48:51-2.

33. Wright EF. Medial pterygoid trismus (myospasm) following inferior alveolar nerve block: case report and literature review. Gen Dent 2011;59:64-7.

34. Ethunandan M, Tran AL, Anand R, Bowden J, Seal MT, Brennan PA. Needle breakage following inferior alveolar nerve block: implications and management. Br Dent J 2007;202:395-7.

35. Chevalier V, Arbab-Chirani R, Tea SH, Roux M. Facial palsy after inferior alveolar nerve block: case report and review of the literature. Int J Oral Maxillofac Surg 2010;39:1139-42.

How to cite this article: Jang HY, Han SJ. Measurement of mandibular lingula location using cone-beam computed tomography and internal oblique ridge-guided inferior alveolar nerve block. J Korean Assoc Oral Maxillofac Surg 2019;45:158-66. https://doi. org/10.5125/jkaoms.2019.45.3.158 